\title{
The Hedging Effectiveness of Stock Index Futures: Evidence for the S\&P CNX Nifty Index Traded in India
}

Kailash Chandra Pradhan*

Abstract:

This study evaluates optimal hedge ratios and the hedging effectiveness of stock index futures. The optimal hedge ratios are estimated from the ordinary least square (OLS) regression model, the vector autoregression model (VAR), the vector error correction model (VECM) and multivariate generalized autoregressive conditional heteroskedasticity (M-GARCH) models such as VAR-GARCH and VEC-GARCH using the S\&P CNX Nifty index and its futures index. Hedging effectiveness is measured in terms of within sample and out of sample risk-return trade-off at various forecasting horizons. The analysis found that the VEC-GARCH time varying hedge ratio provides the greatest portfolio risk reduction and generates the highest portfolio returns.

Keywords: Hedging, M-GARCH, Forecast horizons, S\&P CNX Nifty futures

JEL: G, G1

DOI: $10.2478 / \mathrm{v} 10033-011-0010-2$

\section{Introduction}

A stock index futures contract is an agreement between a buyer and seller to buy or sell a specified quantity of security that matches the underlying index on a future date and for an agreed upon price. They are traded on organized exchanges and feature highly standardized contract terms in all aspects except price. Therefore, the clearing and the settlement are facilitated and can be guaranteed by the clearinghouse against the defaults of market participants.

Futures buyers make profits when the contract settlement price is higher than the price at which they traded it and suffer losses when the contract settlement price is lower. The position of futures sellers is opposite and symmetrical. Since the settlement price at maturity coincides with the value of the underlying index, the futures price bears a close relationship with the index value during the lifetime of the contract, which is enforced by the activity of arbitrageurs on both markets. The link with the underlying stock market and their liquidity makes the index futures important means for price discovery and risk transfer. The essence of the price discovery function depends on whether new information is reflected first in the futures markets or spot markets. Hedging is a process of reducing exposure to risk, and it is an act that reduces the price risk of a certain position in the spot market.

This paper provides an empirical investigation of the risk transfer functions of the futures market. Hedging with stock index futures applies directly to the management of stock portfolios. An optimal hedge ratio is usually defined as the proportion of a spot position that should be covered with an opposite position on a futures market. Still in the literature of futures trading, there is a continuous argument in estimating optimal hedge ratios. The hedgers need to hold a certain amount of futures contracts in order for them to hedge their spot assets on hand. Therefore, it is necessary to estimate how many futures contracts should be seized for each unit of spot

* Kailash Chandra Pradhan

National Council of Applied Economic Research

(NCAER), New Delhi-110002.

E-mail: kailasheco@gmail.com 
asset and very important to calculate the appropriate hedge ratio.

Hedging strategy is measured by the extent to which it reduces risk and many techniques have been developed and applied to find the optimal hedge ratio $(\mathrm{OHR})$ with the aim of reducing risk. Early investigation of hedging includes Working (1953), Johnson (1960), Stein (1961) and Ederington (1979). It postulates that the objective of hedging is to minimize the variance of the spot portfolio held by the investor. Therefore, the hedge ratio that generates the minimum portfolio variance should be the optimal hedge ratio, which is also known as the minimum variance hedge ratio. A large body of research has been developed in the estimation and evaluation of optimal hedging strategies.

In empirical investigations, the hedge ratio varies according to the conditioning information adopted. The earlier studies concluded that the conventional regression approach to optimal hedge ratio estimation fails to take proper account of all of the relevant conditioning information available to hedgers when they make hedging decisions and implicitly assumes that the covariance matrix of spot and futures prices, and hence optimal hedge ratios, are constant over time (Myers, 1991). The studies by Park and Switzer (1995a, 1995b), Lypny and Powalla (1998), Koutmos and Pericli (1998), Lien and Tse (1999), Floros and Vougas (2004), Bryant and Haigh (2005) and Bhaduri and Sethu Durai (2007) also supported the findings and came to similar conclusions. The vector auto regression (VAR) method incorporates the history of both spot and futures prices as conditional information, whereas the error correction model adds the previous basis as a conditioning variable. Statistical properties, for instance the cointegrations between the spot and futures prices, have been documented to support the information value of the lagged prices. Also, vector auto regressive and error correction models ignore the time varying nature of hedge ratios. Thus, multivariate generalized autoregressive conditional heteroscedasticity (M-GARCH) equations are adopted to describe the conditional second moments of the spot and futures prices. They concluded that the constant hedge ratio does not consider the joint distribution of the spot and futures varies over time and that the multivariate GARCH provides a flexible and consistent framework for estimating the time-varying hedge ratio by considering the conditional variance and covariance of the spot and futures prices. Therefore, the generalized auto regressive conditional heteroscedasticity (GARCH) model is incorporated with the bivariate vector auto regression (VAR) and vector error correction (VEC) models, which are known as: the VAR-GARCH and VEC-GARCH models. Based on the above background, the present paper compares the effectiveness of hedge ratios estimated from the ordinary least square regression, VAR, VECM and time varying M-GARCH models (i.e. VAR-GARCH and VECGARCH models).

The rest of the paper is structured as follows. After a brief introduction to the subject in Section 1, Section 2 presents the methodology and data of the study. Empirical results and discussions are presented in Section 3 and concluding remarks are presented in Section 4.

\section{Methodology and Data}

The present study employs regression, VAR, VECM and time varying M-GARCH models (i.e. VAR-GARCH and VECGARCH models) to determine optimal hedge ratios. Then, the performance of the hedge ratios is compared to assess whether the more advanced time varying hedge ratios calculated from Bollerslev, Engle and Wooldridge's (1988) Multivariate-GARCH model can provide more efficiency than other constant hedge ratios from the regression model, the Bivariate VAR model and the Vector Error-Correction Model. This study focuses on five different methods for estimating the hedge ratios and testing their effectiveness for both forecasted in-sample and out-samples data with 1,5,10 \& 20 day horizons.

\section{Model 1: The Conventional Regression Method}

The conventional approach in estimating minimum variance hedge ratio (MVHR) relies upon the simple regression method. Let St and Ft be logged spot and futures prices, respectively, the one period minimum variance constant hedge ratio can be estimated from the expression:

$$
\Delta \mathrm{S}_{\mathrm{t}}=\alpha+\beta \Delta \mathrm{F}_{\mathrm{t}}+\varepsilon_{\mathrm{t}}
$$

Where, $\varepsilon_{\mathrm{t}}$ is the error term from OLS estimation, $\Delta S t$ and $\Delta F t$ representing spot and futures price changes. $\beta$, is the estimated optimal hedge ratio.

\section{Model 2: The Bivariate VAR Model}

The conventional regression method ignores many information variables that may be incorporated into models. Sometimes, previous price movements in the 
spot and futures markets may affect the current price movements. The regression model is invalid due to the fact that the residuals are autocorrelated. In order to eliminate the serial correlation, the following bivariate VAR model incorporates these considerations.

$$
\begin{aligned}
& \Delta \mathrm{S}_{\mathrm{t}}=\alpha_{\mathrm{s}}+\sum_{\mathrm{i}=1}^{\mathrm{n}} \beta_{\mathrm{si}} \Delta \mathrm{S}_{\mathrm{t}-\mathrm{i}}+\sum_{\mathrm{i}=1}^{\mathrm{n}} \gamma_{s i} \Delta \mathrm{F}_{\mathrm{t}-i}+\varepsilon_{\mathrm{st}} \\
& \Delta \mathrm{F}_{\mathrm{t}}=\alpha_{\mathrm{f}}+\sum_{\mathrm{i}=1}^{\mathrm{n}} \beta_{\mathrm{fi}} \Delta \mathrm{S}_{\mathrm{t}-\mathrm{i}}+\sum_{\mathrm{i}=1}^{\mathrm{n}} \gamma_{\mathrm{fi}} \Delta \mathrm{F}_{\mathrm{t}-\mathrm{i}}+\varepsilon_{\mathrm{ft}}
\end{aligned}
$$

Where, $\left(\varepsilon_{\mathrm{st}}, \varepsilon_{\mathrm{ft}}\right)$ are independently identically distributed (IID) random vectors. Let $\operatorname{var}\left(\varepsilon_{\mathrm{st}}\right)=\sigma_{\text {ss }}$, var $\left(\varepsilon_{\mathrm{ft}}\right)=\sigma_{f f}$ and $\operatorname{cov}\left(\varepsilon_{\mathrm{st}}, \varepsilon_{\mathrm{ft}}\right)=\sigma_{s f}$. The minimum variance hedge ratio is $\sigma_{s f} / \sigma_{f f}$, which is called the VAR hedge ratio.

\section{Model 3: The Error Correction Model}

The bivariate VAR model ignored the effect of cointegration of the two series and it is further addressed in Ghosh (1993), and Lien and Luo (1994). They argue that if the two price series are found to be cointegrated, a VAR model should be estimated along with the errorcorrection term, which accounts for the long-run equilibrium between spot and futures price movements. Thus, a VAR model can be modified as:

$$
\Delta \mathrm{S}_{\mathrm{t}}=\alpha_{\mathrm{s}}+\sum_{\mathrm{i}=1}^{\mathrm{n}} \beta_{\mathrm{si}} \Delta \mathrm{S}_{\mathrm{t}-\mathrm{i}}+\sum_{\mathrm{i}=1}^{\mathrm{n}} \gamma_{s i} \Delta \mathrm{F}_{\mathrm{t}-i}+\lambda_{s} Z_{t-1}+\varepsilon_{\mathrm{st}}
$$

$\Delta \mathrm{F}_{\mathrm{t}}=\alpha_{\mathrm{f}}+\sum_{\mathrm{i}=1}^{\mathrm{n}} \beta_{\mathrm{fi}} \Delta \mathrm{S}_{\mathrm{t}-\mathrm{i}}+\sum_{\mathrm{i}=1}^{\mathrm{n}} \gamma_{\mathrm{fi}} \Delta \mathrm{F}_{\mathrm{t}-\mathrm{i}}+\lambda_{f} Z_{t-1}+\varepsilon_{\mathrm{ft}}$

Where, $\mathrm{Z}_{\mathrm{t}-1}$ is an error correction term with $(1-\delta)$ as cointegrating vector and $\lambda_{s}, \lambda_{f}$ as adjustment parameters, which measure how the dependent variable adjusts to the previous period's deviation from long-run equilibrium. The same procedure of generating the residual series and the minimum variance hedge ratio can be calculated using the VAR model.

\section{Model 4: The Multivariate GARCH Model}

In the above model, they have assumed that that the residuals have constant variances and covariances. In general, GARCH models assume that the conditional variance is affected by its own history and the history of the squared innovations. The advantage of $\mathrm{GARCH}$ models is that they have been able to capture the behavior of financial time series, such as serial correlation in volatility and co-movements in volatilities. The large literature on optimal hedging has extensively used multivariate GARCH models to generate minimum variance hedge ratios. Those studies include Myers (1991), Park \& Switzer (1995a, 1995b), Lypny \& Powalla (1998), Koutmos \& Pericli (1998), Lien \& Tse (1999), Floros and Vougas (2004) and Cotter \& Hanly (2006). From a hedging point of view, the multivariate GARCH models are suitable, because they can estimate jointly the conditional variances and covariances required for a minimum variance hedge ratio. Thus, the multivariate GARCH model is applied to calculate the dynamic hedge ratios that vary over time based on the conditional variance and covariance of the spot and futures prices and generalized from GARCH $(1,1)$. A standard M-GARCH $(1,1)$ model is expressed as:

$$
\begin{aligned}
{\left[\begin{array}{l}
\mathrm{h}_{\mathrm{ss}} \\
\mathrm{h}_{\mathrm{sf}} \\
\mathrm{h}_{\mathrm{ff}}
\end{array}\right]_{t}\left[\begin{array}{l}
\mathrm{c}_{\mathrm{ss}} \\
\mathrm{c}_{\mathrm{sf}} \\
\mathrm{c}_{\mathrm{ff}}
\end{array}\right]_{t} } & {\left[\begin{array}{lll}
\alpha_{11} & \alpha_{12} & \alpha_{13} \\
\alpha_{21} & \alpha_{22} & \alpha_{23} \\
\alpha_{31} & \alpha_{32} & \alpha_{33}
\end{array}\right]\left[\begin{array}{l}
\varepsilon_{\mathrm{s}}^{2} \\
\varepsilon_{s} \varepsilon_{f} \\
\varepsilon_{f}^{2}
\end{array}\right]_{t-1}+} \\
& +\left[\begin{array}{lll}
\beta_{11} & \beta_{12} & \beta_{13} \\
\beta_{21} & \beta_{22} & \beta_{23} \\
\beta_{31} & \beta_{32} & \beta_{33}
\end{array}\right]\left[\begin{array}{l}
\mathrm{h}_{\mathrm{ss}} \\
\mathrm{h}_{\mathrm{sf}} \\
\mathrm{h}_{\mathrm{ff}}
\end{array}\right]_{t-1}
\end{aligned}
$$

Where $h_{s s}, h_{f f}$ are the conditional variances of the errors $\left(\varepsilon_{\mathrm{st}} \varepsilon_{\mathrm{ft}}\right)$ from the mean equations. The M-GARCH process may be incorporated into the bivariate VAR and VEC models. In this model the main equations are the bivariate vector autorgression (VAR) and the vector error correction (VEC) model equations. As the model has a large number of parameters to be estimated, Bollerslev, Engle and Wooldridge (1988) proposed a restricted version of the above model with $\boldsymbol{\alpha}$ and $\boldsymbol{\beta}$ matrices having only diagonal elements which allows for a time-varying conditional variance. The diagonal representation of the conditional variances elements $h_{\text {ss }}$ and $h_{\text {ff }}$ and the covariance element $h_{\text {sf }}$ can be expressed as: 


$$
\begin{aligned}
& \mathrm{h}_{\mathrm{ss}, \mathrm{t}}=c_{s s}+\alpha_{11} \varepsilon_{s, t-1}^{2}+\beta_{11} \mathrm{~h}_{\mathrm{ss}, \mathrm{t}-1} \\
& \mathrm{~h}_{\mathrm{sf}, \mathrm{t}}=c_{s f}+\alpha_{22} \varepsilon_{s, t-1} \varepsilon_{f, t-1}+\beta_{22} \mathrm{~h}_{\mathrm{sf}, \mathrm{t}-1} \\
& \mathrm{~h}_{\mathrm{ff}, \mathrm{t}}=c_{f f}+\alpha_{33} \varepsilon_{f, t-1}^{2}+\beta_{33} \mathrm{~h}_{\mathrm{ff}, \mathrm{t}-1}
\end{aligned}
$$

The time varying hedge ratio has been estimated as the ratio between the covariance of spot and futures prices with the variance of futures prices. So $h_{s, t} / h_{f f, t}$ will be the time varying hedge ratio and hence generates a more realistic time-varying hedge.

\subsection{Estimating Hedging Effectiveness}

In the above, four hedging strategies have been discussed to derive optimal hedge ratios, each of which is based on different econometric theories and involves different degrees of computational complexity. The expost and the ex-ante forecasting methods are then employed to compare the performance of these four types of hedge ratios. Hedging effectiveness is calculated by the variance reduction in the hedged portfolio compared to that of an un-hedged portfolio in each forecasting horizon. The returns on the un-hedged and the hedged portfolios are simply expressed as:

$$
\begin{aligned}
& R_{\text {unhedged }}=S_{t+1}-S_{t} \\
& R_{\text {hedged }}=\left(S_{t+1}-S_{t}\right)-h^{*}\left(F_{t+1}-F_{t}\right)
\end{aligned}
$$

Where $R_{\text {unhedged }}$ and $R_{\text {hedged }}$ are returns on un-hedged and hedged portfolios, respectively. Ft and St are logged futures and spot prices at time period $t$, respectively, $\mathrm{h}^{*}$ is the optimal hedge ratio, and the return on the hedged portfolio is the difference between the return on holding the cash position and corresponding futures position. Similarly, the variance of the un-hedged and hedged portfolio is expressed as:

$$
\begin{aligned}
& V a r_{\text {unhedged }}=\sigma_{s}^{2} \\
& V a r_{\text {hedged }}=\sigma_{s}^{2}+h^{* 2} \sigma_{f}^{2}-2 h * \sigma_{s f}
\end{aligned}
$$

Where $V r_{\text {unhedged }}$ and $V$ r $_{\text {hedged }}$ represent variance of un-hedged and hedged portfolios, respectively. $\sigma_{s}, \sigma_{f}$ and $\sigma_{\mathrm{sf}}$ are standard deviations of spot and futures prices and the covariance between them, respectively. The effectiveness of hedging (HE) can be measured by the percentage reduction in the variance of a hedged portfolio as compared with the variance of an un-hedged portfolio (Ederington, 1979). The variance reduction can be calculated as:

$$
H E=1-\left[\frac{\text { Var }_{\text {HedgedPortfolio }}}{\text { Var }_{\text {UnhedgedPortfolio }}}\right]
$$

$\mathrm{HE}=1$, then the futures contract completely eliminates risk and indicates a $100 \%$ reduction in the variance. When $\mathrm{HE}=0$, then hedging with the futures contract does not reduce risk. The hedging performance of the models may vary according to the hedge horizon. Therefore, hedging effectiveness of the four models will be considered over horizons of 1, 5, 10, 15 and 20 days in this context.

The data set employed in the present study is retrieved from the NSE website. It encompasses the S\&P CNX Nifty Index and the corresponding NSE Stock Index Futures prices on a daily basis for the period of June 12, 2000 to November 28, 2007 summing up to a total of 1871 observations. Only the first 1721 observations are employed in the empirical tests, leaving the last 150 observations starting from April 27, 2007 for an out of sample hedge ratio performance comparison.

\section{Empirical Results and Implications Results of Unit Roots and Cointegration}

In Table (1), the unit root tests for the logged spot of the S\&P CNX Nifty Index and logged futures of the Nifty index with the levels and first differences are presented. The Dickey-Fuller (DF), Augmented Dickey-Fuller (ADF) and Phillips-Perron ( $p p)$ tests have reported to test the stationarity of the series. The results of unit root tests indicate that both series are non-stationary at levels and stationary at the first difference. Therefore, it is necessary to use the Johansen and Juselius (1990) cointegration test between the variables. The results of the cointegration test are presented in Table (2).

The trace and max-eigen value statistics suggest the existence of one cointegrating vector at a 5 percent level of significance. It shows the existence of a long-run relationship between the spot and futures prices.

\subsection{Results of the Optimal Hedge Ratio}

First, the optimal hedge ratio can be derived from the regression in equation-1, where the logged difference of spot prices are regressed on the difference of logged futures prices. Table (3) presents the results of the 
regression model to obtain the optimal hedge ratio. The optimal hedge ratio (OHR) is 0.922355 .

According to Akaike's Information Criteria (AIC) and the Schwarz Bayesian Criterion (SBC), the appropriate lag length of the bivariate VAR model is two. The test results of the optimal hedge ratio (OHR) from bivariate auto regression (BVAR) and the vector error correction (VEC) model are presented in Tables (4) and (5) simultaneously. In the vector error correction model (VECM), the coefficients of the error-correction term in the futures equation are significant as indicated by the large values of the $t$-ratios. It is noticed that $\lambda_{f}=0.291372$. This implies that the futures price series $F t$ has a greater speed of adjustment to the previous period's deviation from long-run equilibrium than the spot price series. This finding is consistent with the fact that on the delivery date of each contract the futures price has to adjust itself to the prevailing spot price. The hedge ratios of both models are estimated using the variance and covariance of the residuals.

In the Bivariate VAR model, $\operatorname{var}\left(\varepsilon_{\text {st }}\right)=\sigma_{s s}$ $=0.0000394, \operatorname{var}\left(\varepsilon_{\mathrm{ft}}\right)=\sigma_{f f}=0.0000438$ and $\operatorname{cov}$ $\left(\varepsilon_{\mathrm{st}}, \varepsilon_{\mathrm{ft}}\right)=\sigma_{s f}=0.0000405$. The minimum variance hedge ratio as per VAR model result is $\sigma_{s f} / \sigma_{f f}=0.92527$. In the VECM model, $\operatorname{var}\left(\varepsilon_{\text {st }}\right)=\sigma_{s s}=0.0000394$, var $\left(\varepsilon_{\mathrm{ft}}\right)=\sigma_{f f}=0.0000434$ and $\operatorname{cov}\left(\varepsilon_{\mathrm{st}}, \varepsilon_{\mathrm{ft}}\right)=\sigma_{s f}$ $=0.0000404$. The minimum variance hedge ratio is $\sigma_{s f} /$ $\sigma_{f f}=0.92974$, which is the VECM optimum hedge ratio. As expected, and in line with most of the previous studies by Ghosh (1993) and others, the hedge ratio estimated by the error-correction model is greater than that obtained from other models. The reason is that it takes into account the tighter long-run equilibrium relationship between the spot and futures prices. The hedger ignorant of the cointegrating relationship between futures and spot prices is likely to take a smaller-than-optimal futures position.

The study is extended to examine the efficiency of both the Bivariate VAR model and the VEC model. The features of the residuals are investigated. Figures (1) and (2) plot the residuals from the BVAR and VEC models simultaneously. The plots of the actual values of the residuals from the BVAR and VEC models in Figures (1) and (2) simultaneously display volatility clustering even though the mean seems constant. The variance of the series changes through time and large (small) changes tend to be followed by large (small) changes of either sign. This characteristic has been commonly established in most economic time series by Mandelbrot $(1963,1967)$, Klien (1977), Engle (1982) etc. and it clearly shows the presence of an autoregressive conditional heteroskedasticity (ARCH) effect.

Another way to test for the presence of ARCH effects has been suggested by McLeod and Li (1983). According to McLeod and Li (1983), a casual examination of the sample autocorrelation function of the mean equation squared residuals for a significant Q-statistic at a given lag can be used to infer the presence of ARCH effects. The Ljung-Box Q-statistic at lag $n$ is a test statistic for the null hypothesis that there is no autocorrelation up to order $n$. For squared residuals, the autocorrelation functions (ACF) and partial autocorrelation functions (PACF) from equations (2) and (3) which are presented in Table (6). Table (7) presents ACF and PACF from equations (4) and (5). They are all highly significant, confirming the presence of ARCH effects.

The above tests have all indicated the existence of heteroskedasticity in the VAR and VEC models. Therefore, it confirms the necessity of M-GARCH modeling to estimate the conditional variance and covariance for calculating time varying hedge ratios. This paper estimated the bivariate vector autorgression (VAR) and vector error correction (VEC) multivariate GARCH models of Bollerslev, Engle and Wooldridge (1988), in particular, the mean equations (first moment) modeled with bivariate vector autorgression (VAR) and vector error correction (VEC) models. In addition, time-varying variances and covariances are taken into account by modeling the second moment with VAR-GARCH and VEC$\mathrm{GARCH}$ models. The estimation from variances and covariances and time-varying hedge ratios based on a GARCH model are expected to give better results. The estimated results are presented in Tables (8) and (9) from the VAR-GARCH and VEC-GARCH, respectively, in equations (7)-(9). The parameter estimates are all positive, definite and highly significant. Furthermore, the sum of the coefficients for each equation is close to unit, (for example: $c_{s s}+\alpha_{s s}+\beta_{s s}=0.9776, c_{s f}+\alpha_{s f}+\beta_{s f}$ $=0.9786$ and $c_{f f}+\alpha_{f f}+\beta_{f f}=0.9820$ in the VAR-GARCH model and $c_{s s}+\alpha_{s s}+\beta_{s s}=0.9775, c_{s f}+\alpha_{s f}+\beta_{s f}$ $=0.9734$ and $c_{f f}+\alpha_{f f}+\beta_{f f}=0.9814$ in the VEC-GARCH model) which suggests the persistence of ARCH effects in 
the data sets. This particular phenomenon in the GARCH model is examined by Engle and Bollerslev (1986) and termed an integrated generalized auto regressive conditional heteroskedasticity (IGARCH) model. This implies that current information remains important for forecasts of the conditional variance at all horizons.

The mean values of the time varying hedge ratios of the VAR-GARCH and VEC-GARCH models are 0.95731 and 0.96375 , respectively. Hence, the hedge ratio estimated by VEC-GARCH models is greater than the values obtained from all other models. Therefore, hedge ratios estimated by the VEC-GARCH model should be more efficient in reducing the risk of spot prices. The optimal hedge ratios (OHR) estimated from the four different models are listed in Table (10).

\subsection{Results of Hedging Effectiveness}

Using the above estimation results, this paper also calculates the post-sample hedge ratios and compares the hedging performance of each strategy. In the sample, daily data on the S\&P CNX Nifty Index and the corresponding NSE Stock Index Futures prices have been considered for the period from June 12, 2000 to April 26, 2007, summing up to a total of 1871 observations, and the 150 observations starting from April 27, 2007 to November 28, 2007 have been considered for an out of sample hedge ratio performance comparison. The results for the in-sample and post-sample performances are presented to obtain the hedging effectiveness with 1, 5, 10, 15 and 20 day horizons in Tables (11)-(16).

The different hedging strategies for within sample and out of sample have been presented. The study considers hedge horizons of 1, 5, 10, 15 and 20 days. The mean returns, variance returns and average variance reduction have been estimated for 1, 5, 10, 15 and 20 day horizons for both within sample and out of sample validations.

A hedging strategy is effective only if the mean return from the strategy is higher than the competing strategies and it reduces a significant portion of the variance with respect to its unhedged strategy. Table (11) gives within sample mean returns, Table (12) gives within variance returns and Table (13) gives the percentage in variance reduction for different hedging ratios. These tables show the trade-off between risk and returns. In the one-day forecasting horizon, OLS gives the best hedging strategy because it generates the greatest mean returns, lowest variance returns and highest percentage in variance reduction compared to other models. In the other day forecasting horizons, OLS gives the greatest mean return, highest variance return and lowest variance in reduction compared to other models. Hence it provides the greatest risk. Therefore, the results reveal that the OLS provides the highest mean returns in all forecasting horizons and provides the lowest variance reduction in longer forecasting horizons, except for one-day forecasting horizons in the case of within-sample forecasts. The results show that the time-varying VAR-GARCH and VECGARCH give the best hedge strategy in the long horizons. The VEC-GARCH model generates the lowest return and highest percentage in variance reduction in the longer forecasting horizons compared to the other four models except for one-day forecasting horizons. Overall, in the case of the within sample, the VEC-GARCH provides the best hedging strategy in the long horizons and OLS provides the best hedging strategy in the short horizons.

Tables (14) and (15) show the out of sample mean returns and variance returns, respectively. Table (16) shows the percentage in variance reduction for the out of sample. In the one-day horizon, the OLS gives the lowest mean returns, lowest variance returns and highest percentage in variance reduction. It generates the lowest risk compared to other models in the case of one-day forecasting horizons. In the case of 5, 10, 15 and 20 day forecasting horizons, VEC-GARCH provides the highest mean returns, lowest variance returns and highest percentage of variance reduction. It generates the smallest risk compared to other models such as: the OLS, VAR, VECM and VAR-GARCH. Overall, the time varying VEC-GARCH provides the best hedging strategy compared to the other models.

\section{Conclusion}

The present study examines the performance of various hedge ratios estimated from different econometric models and compares them in terms of the risk-return trade-offs of the within sample and out of sample forecasting horizons. In the one-day within sample forecasting horizons, the conventional regression model (OLS) provides the best hedging strategy compared to other models. On the other hand, the hedge ratio calculated from the conventional regression model performs the worst in terms of reducing portfolio variance, but yields the highest rate of return in the case of 5, 10, 15 and 20 day forecasting horizons. In the long within sample forecasting horizons, VEC-GARCH generates the best hedging strategy with the lowest 
mean returns, lowest variance returns and highest percentage in variance reduction. In the performance of hedge ratios, the out of sample forecast gives the highest returns in all horizons. The OLS model provides the lowest mean return, lowest variance return and highest percentage in variance reduction in the one-day forecasting horizon. In addition, the VEC-GARCH provides the lowest variance returns and highest percentage in variance reduction in 5, 10, 15 and 20 day forecasting horizons. It generates the lowest risk with the highest returns. By and large, the in-sample and out-of-sample forecasts conclude that the time varying VEC-GARCH gives the best hedge strategy compared to the OLS, VAR and VECM and VAR-GARCH models. [

\section{References}

Bhaduri, S. N. and S. R. Sethu Durai (2007). Optimal hedge ratio and hedging effectiveness of stock index futures: Evidence from India. NSE Working Papers, 1-19.

Bollerslev, T., R. F. Engle and J. M. Wooldridge (1988). A capital asset pricing model with time-varying covariances. Econometrica, 96: 116131.

Bryant, H. L. and M.S. Haigh (2005). Derivatives pricing model and time-series approaches to hedging: A comparison. The Journal of Futures Markets, 25: 613-641.

Cotter, J. and J. Hanly (2006). Reevaluating hedging performance. The Journal of Futures Market, 26: 677-702.

Ederington, L. (1979). The hedging performance of the new futures markets. Journal of Finance, 34: 157-70.

Engel, R.F. (1982). Autoregressive conditional heteroskedasticity with estimates of the variance of U.K. Inflation. Econometrica, vol-50: 987-1008.

Engle, R. F. and T. Bollerslev (1986). Modeling the persistence of conditional variances. Econometric Reviews, 5: 1-87.

Floros, C. and D. V. Vougas (2004). Hedge ratios in Greek stock index futures market. Applied Financial Economics, 14: 1125-36.

Ghosh, A. (1993). Hedging with stock index futures: Estimation and forecasting with error correction model. The Journal of Futures Markets, 13: 743-752.

Johansen, S. and K. Juselius (1990). Maximum likelihood estimation and inference on cointegration with application to the demand for money. Journal of Econometrics, 53: 211-244.

Johnson, L. (1960). The theory of hedging and speculation in commodity futures. Review of Economic Studies, 27: 139-51.

Klien, B. (1977). The demand for quality-adjusted cash balances: Price uncertainty in the U. S. demand for money function. Journal of Political Economy, 85, 693-715.

Koutmos, G. and A. Pericli (1998). Dynamic hedging of commercial paper with T-bills futures. The Journal of Futures Markets, 18: 925-38.

Lien, D. and X. Lou (1994). Multiperiod hedging in the presence of conditional heteroskedasticity. The Journal of Futures Markets, 14: $927-$ 955.

Lien, D. and Y. K. Tse (1999). Fractional cointegration and futures hedging. The Journal of Futures Markets, 19: 457-74.

Lypny, G. and M. Powalla (1998). The hedging effectiveness of DAX futures. The European Journal of Finance, 4:4: 345 - 355.
Mandelbrot, B. (1963). The variation of certain speculative prices. Journal of Business, 36: 394-419.

Mandelbrot, B. (1967). The variation of some other speculative prices. Journal of Business, 40: 393-413.

McLeod, A. I. and W. K. Li (1983). Diagnostic checking of ARMA time's series models using squared residual autocorrelations. Journal of Time Series Analysis, 4: 269-273.

Myers, R. J. (1991). Estimating time-varying optimal hedge ratios on futures markets. Journal of Futures Market, 11: 39-53.

Park, T. and L. N. Switzer (1995a). Bivariate GARCH estimation of the optimal hedge ratios for stock index futures: a note. The journal of Futures market, 15: 61-67.

Park, T. and L. N. Switzer (1995b). Time-varying distributions and the optimal hedge ratios for stock index futures. Applied Financial Economics, 5: 131-137.

Stein, J.L. (1961). The simultaneous determination of spot and futures prices. American Economic Review, 51:1012-25.

Working, H. (1953). Futures trading and hedging. American Economic Review, 43: 314-43.

www.nseindia.com 


\section{Tables and Figures}

\begin{tabular}{|c|c|c|c|c|c|c|}
\hline \multirow[t]{2}{*}{ Constraint } & \multicolumn{2}{|c|}{ DF } & \multicolumn{2}{|c|}{ ADF } & \multicolumn{2}{|c|}{ PP } \\
\hline & Levels & Difference & Levels & Difference & Levels & Difference \\
\hline \multicolumn{7}{|c|}{ Logged Spot price } \\
\hline Intercept & 1.28 & $-7.79^{*}$ & 0.82 & $-30.43^{*}$ & 0.70 & $-37.52^{*}$ \\
\hline Intercept and Trend & -0.51 & $-29.63^{*}$ & -2.28 & $-30.54^{*}$ & -2.31 & $-37.58^{*}$ \\
\hline \multicolumn{7}{|c|}{ Logged Futures price } \\
\hline Intercept & 1.16 & $-4.14^{*}$ & 0.73 & $-40.09^{*}$ & 0.72 & $-40.07^{*}$ \\
\hline Intercept and Trend & -0.54 & $-16.76^{*}$ & -2.33 & $-40.18^{*}$ & -2.34 & $-40.18^{*}$ \\
\hline
\end{tabular}

Note: * denotes $1 \%$ level of significance

Table 1: The Unit Root Test

\begin{tabular}{|c|c|c|c|c|}
\hline Null Hypothesis & $\begin{array}{l}\text { Alternative } \\
\text { Hypothesis }\end{array}$ & & & $5 \%$ critical value \\
\hline$\lambda_{\text {trace }}$ tests & & Eigen value & $\left(\lambda_{\text {trace }}\right)$ Stat. & \\
\hline$r=0 *$ & $r>0$ & 0.047 & 83.61 & 15.49 \\
\hline$r \leq 1$ & $r>1$ & 0.0002 & 0.38 & 3.84 \\
\hline$\lambda_{\max }$ test & & Eigen value & $\lambda_{\max }$ Stat. & \\
\hline$r=0 *$ & $r=1$ & 0.047 & 83.23 & 14.26 \\
\hline$r=1$ & $r=2$ & 0.0002 & 0.38 & 3.84 \\
\hline
\end{tabular}

Table 2: Cointegration Tests of Johansen

\begin{tabular}{rrcl}
\hline & & Coefficients & \multicolumn{1}{c}{ t-Statistic } \\
\hline A & & 0.000023 & 0.62917 \\
B & & $0.922355^{*}$ & 170.0909 \\
$\mathrm{R}^{2}$ & 0.943946 & & \\
\hline
\end{tabular}

Note: * denotes $1 \%$ level of significance

Table 3: Results of Regression Model

\begin{tabular}{|c|c|c|c|c|}
\hline \multicolumn{5}{|c|}{$\begin{array}{l}\Delta \mathrm{S}_{\mathrm{t}}=\alpha_{\mathrm{s}}+\sum_{\mathrm{i}=1}^{\mathrm{n}} \beta_{\mathrm{si}} \Delta \mathrm{S}_{\mathrm{t}-\mathrm{i}}+\sum_{\mathrm{i}=1}^{\mathrm{n}} \gamma_{s i} \Delta \mathrm{F}_{\mathrm{t}-i}+\varepsilon_{\mathrm{st}} \\
\Delta \mathrm{F}_{\mathrm{t}}=\alpha_{\mathrm{f}}+\sum_{\mathrm{i}=1}^{\mathrm{n}} \beta_{\mathrm{fi}} \Delta \mathrm{S}_{\mathrm{t}-\mathrm{i}}+\sum_{\mathrm{i}=1}^{\mathrm{n}} \gamma_{\mathrm{fi}} \Delta \mathrm{F}_{\mathrm{t}-\mathrm{i}}+\varepsilon_{\mathrm{ft}}\end{array}$} \\
\hline & $\Delta \mathrm{S}_{\mathrm{t}}$ & t-statistics & $\Delta F_{\mathrm{t}}$ & t-statistics \\
\hline$\alpha_{i} i=s, f$ & $0.000265^{* * *}$ & 1.74656 & $0.000266^{* * *}$ & 1.65983 \\
\hline$\Delta \mathrm{S}_{\mathrm{t}-1}$ & $0.289698^{*}$ & 2.71718 & $0.561593^{*}$ & 4.99910 \\
\hline$\Delta \mathrm{S}_{\mathrm{t}-2}$ & -0.043978 & -0.42273 & 0.134053 & 1.22291 \\
\hline$\Delta \mathrm{F}_{\mathrm{t}-1}$ & $-0.17898^{* * *}$ & -1.76728 & $-0.484915^{*}$ & -4.54418 \\
\hline$\Delta \mathrm{F}_{\mathrm{t}-2}$ & -0.051473 & -0.51527 & $-0.207406^{* *}$ & -1.97051 \\
\hline
\end{tabular}

Note: ${ }^{*}$ denotes $1 \%$ level of significance, ${ }^{* *}$ denotes $5 \%$ level of significance and ${ }^{* * *}$ denotes $10 \%$ level of significance.

Table-4: Estimates of Bivariate Vector Autorgression (VAR) Model 


\begin{tabular}{|c|c|c|c|c|}
\hline \multicolumn{4}{|c|}{$\Delta \mathrm{S}_{\mathrm{t}}=\alpha_{\mathrm{s}}+\sum_{\mathrm{i}=1}^{\mathrm{n}} \beta_{\mathrm{si}} \Delta \mathrm{S}_{\mathrm{t}-\mathrm{i}}+\sum_{\mathrm{i}=1}^{\mathrm{n}} \gamma_{s i} \Delta \mathrm{F}_{\mathrm{t}-i}+\lambda_{s} Z_{t-1}+\varepsilon_{\mathrm{st}}$} & \\
\hline$\alpha_{i} i=s, f$ & $0.000266^{* * *}$ & 1.75166 & 0.000267 & 1.67676 \\
\hline$\Delta \mathrm{S}_{\mathrm{t}-1}$ & $0.219787^{* *}$ & 1.90479 & $0.385085^{*}$ & 3.17839 \\
\hline$\Delta \mathrm{S}_{\mathrm{t}-2}$ & -0.090679 & -0.83880 & 0.016145 & 0.14223 \\
\hline$\Delta F_{t-1}$ & -0.109270 & -0.98955 & $-0.308906^{*}$ & -2.66419 \\
\hline$\Delta \mathrm{F}_{\mathrm{t}-2}$ & -0.006494 & -0.06254 & -0.093845 & -0.86081 \\
\hline$Z_{t-1}$ & 0.115407 & 1.58047 & $0.291372^{*}$ & 3.80021 \\
\hline
\end{tabular}

Note: * denotes $1 \%$ level of significance, ${ }^{* *}$ denotes $5 \%$ level of significance and ${ }^{* * *}$ denotes $10 \%$ level of significance.

Table-5: Estimates of Vector Error Correction (VEC) Model

\begin{tabular}{|c|c|c|c|c|c|c|c|c|}
\hline \multirow[b]{2}{*}{ Lags } & \multicolumn{4}{|c|}{ Equation-2 } & \multicolumn{4}{|c|}{ Equation-3 } \\
\hline & $A C$ & PAC & Q-Stat & Prob. & $A C$ & PAC & Q-Stat & Prob. \\
\hline 1 & 0.503 & 0.503 & 435.89 & 0.000 & 0.433 & 0.433 & 322.56 & 0.000 \\
\hline 2 & 0.230 & -0.031 & 526.90 & 0.000 & 0.164 & -0.029 & 368.65 & 0.000 \\
\hline 3 & 0.138 & 0.046 & 559.51 & 0.000 & 0.135 & 0.092 & 400.11 & 0.000 \\
\hline 4 & 0.120 & 0.052 & 584.51 & 0.000 & 0.105 & 0.020 & 419.29 & 0.000 \\
\hline 5 & 0.107 & 0.029 & 604.16 & 0.000 & 0.100 & 0.050 & 436.55 & 0.000 \\
\hline 6 & 0.068 & -0.009 & 612.02 & 0.000 & 0.059 & -0.013 & 442.56 & 0.000 \\
\hline 7 & 0.050 & 0.014 & 616.38 & 0.000 & 0.035 & 0.004 & 444.66 & 0.000 \\
\hline 8 & 0.082 & 0.061 & 628.10 & 0.000 & 0.081 & 0.068 & 456.01 & 0.000 \\
\hline 9 & 0.106 & 0.044 & 647.61 & 0.000 & 0.147 & 0.099 & 493.19 & 0.000 \\
\hline 10 & 0.074 & -0.013 & 657.16 & 0.000 & 0.071 & -0.047 & 501.95 & 0.000 \\
\hline 11 & 0.041 & -0.006 & 660.05 & 0.000 & 0.036 & 0.008 & 504.22 & 0.000 \\
\hline 12 & 0.084 & 0.076 & 672.13 & 0.000 & 0.058 & 0.028 & 509.97 & 0.000 \\
\hline 13 & 0.086 & 0.004 & 684.96 & 0.000 & 0.088 & 0.049 & 523.45 & 0.000 \\
\hline 14 & 0.069 & 0.007 & 693.33 & 0.000 & 0.052 & -0.026 & 528.11 & 0.000 \\
\hline 15 & 0.052 & 0.007 & 697.94 & 0.000 & 0.041 & 0.023 & 531.09 & 0.000 \\
\hline 16 & 0.062 & 0.031 & 704.55 & 0.000 & 0.043 & 0.011 & 534.34 & 0.000 \\
\hline 17 & 0.043 & -0.023 & 707.73 & 0.000 & 0.038 & -0.003 & 536.83 & 0.000 \\
\hline 18 & 0.044 & 0.018 & 711.02 & 0.000 & 0.039 & -0.001 & 539.45 & 0.000 \\
\hline 19 & 0.031 & -0.003 & 712.67 & 0.000 & 0.025 & 0.004 & 540.50 & 0.000 \\
\hline 20 & 0.059 & 0.048 & 718.66 & 0.000 & 0.040 & 0.030 & 543.23 & 0.000 \\
\hline
\end{tabular}

Table 6: Squared residuals from the Bivariate VAR Model 


\begin{tabular}{|c|c|c|c|c|c|c|c|c|}
\hline \multirow[b]{2}{*}{ Lags } & \multicolumn{4}{|c|}{ Equation-4 } & \multicolumn{4}{|c|}{ Equation-5 } \\
\hline & $A C$ & PAC & Q-Stat & Prob. & $A C$ & PAC & Q-Stat & Prob. \\
\hline 1 & 0.501 & 0.501 & 431.71 & 0.000 & 0.417 & 0.417 & 299.73 & 0.000 \\
\hline 2 & 0.227 & -0.032 & 520.56 & 0.000 & 0.154 & -0.025 & 340.41 & 0.000 \\
\hline 3 & 0.14 & 0.052 & 554.45 & 0.000 & 0.139 & 0.101 & 373.77 & 0.000 \\
\hline 4 & 0.118 & 0.044 & 578.5 & 0.000 & 0.098 & 0.007 & 390.2 & 0.000 \\
\hline 5 & 0.103 & 0.029 & 596.85 & 0.000 & 0.091 & 0.049 & 404.47 & 0.000 \\
\hline 6 & 0.067 & -0.006 & 604.56 & 0.000 & 0.056 & -0.011 & 409.84 & 0.000 \\
\hline 7 & 0.051 & 0.014 & 609.07 & 0.000 & 0.036 & 0.008 & 412.02 & 0.000 \\
\hline 8 & 0.082 & 0.06 & 620.74 & 0.000 & 0.078 & 0.062 & 422.6 & 0.000 \\
\hline 9 & 0.107 & 0.047 & 640.53 & 0.000 & 0.145 & 0.103 & 459.18 & 0.000 \\
\hline 10 & 0.077 & -0.01 & 650.87 & 0.000 & 0.078 & -0.034 & 469.71 & 0.000 \\
\hline 11 & 0.04 & -0.011 & 653.68 & 0.000 & 0.034 & -0.003 & 471.71 & 0.000 \\
\hline 12 & 0.083 & 0.077 & 665.49 & 0.000 & 0.055 & 0.026 & 476.91 & 0.000 \\
\hline 13 & 0.09 & 0.011 & 679.47 & 0.000 & 0.096 & 0.063 & 492.8 & 0.000 \\
\hline 14 & 0.068 & 0.012 & 687.48 & 0.000 & 0.047 & -0.036 & 496.66 & 0.000 \\
\hline 15 & 0.052 & 0.01 & 692.1 & 0.000 & 0.042 & 0.029 & 499.66 & 0.000 \\
\hline 16 & 0.062 & 0.031 & 698.77 & 0.000 & 0.044 & 0.007 & 503.04 & 0.000 \\
\hline 17 & 0.042 & -0.023 & 701.88 & 0.000 & 0.035 & -0.001 & 505.23 & 0.000 \\
\hline 18 & 0.046 & 0.021 & 705.48 & 0.000 & 0.04 & 0.1 & 508.01 & 0.000 \\
\hline 19 & 0.034 & -0.003 & 707.46 & 0.000 & 0.029 & 0.006 & 509.49 & 0.000 \\
\hline 20 & 0.06 & 0.048 & 713.74 & 0.000 & 0.042 & 0.03 & 512.5 & 0.000 \\
\hline
\end{tabular}

Table 7: Squared residuals from the VEC Model

\begin{tabular}{cccc}
\hline Variable & Coefficient & t-Statistic & Probability \\
\hline$c_{s s}$ & $9.28 \mathrm{E}-07$ & 1.273718 & 0.2029 \\
$c_{s f}$ & $8.64 \mathrm{E}-07$ & 1.241838 & 0.2145 \\
$c_{f f}$ & $7.64 \mathrm{E}-07$ & 1.293859 & 0.1959 \\
$\alpha_{s s}$ & 0.000699 & 2.299586 & 0.0216 \\
$\alpha_{s f}$ & 0.000566 & 1.977283 & 0.0482 \\
$\alpha_{f f}$ & 0.000453 & 1.846006 & 0.0651 \\
$\beta_{s s}$ & 0.976941 & 55.85609 & 0.0000 \\
$\beta_{s f}$ & 0.978078 & 57.01693 & 0.0000 \\
$\beta_{f f}$ & 0.981563 & 70.74960 & 0.0000 \\
\hline
\end{tabular}

Table 8: The Estimates of the VAR-GARCH Model 


\begin{tabular}{cccc}
\hline Variable & Coefficient & t-Statistic & Probability \\
\hline$c_{s s}$ & $9.30 \mathrm{E}-07$ & 5.883056 & 0.0000 \\
$c_{s f}$ & $8.74 \mathrm{E}-07$ & 5.858305 & 0.0000 \\
$c_{f f}$ & $7.84 \mathrm{E}-07$ & 5.640412 & 0.0000 \\
$\alpha_{s s}$ & 0.000915 & 4.440057 & 0.0000 \\
$\alpha_{s f}$ & 0.000788 & 4.740649 & 0.0000 \\
$\alpha_{f f}$ & 0.000652 & 4.909928 & 0.0000 \\
$\beta_{s s}$ & 0.976672 & 253.2110 & 0.0000 \\
$\beta_{s f}$ & 0.977556 & 261.2652 & 0.0000 \\
$\beta_{f f}$ & 0.980696 & 292.2567 & 0.0000 \\
\hline
\end{tabular}

Table 9: The Estimates of the VEC-GARCH Model

\begin{tabular}{ll}
\hline Method & OHR \\
\hline OLS & 0.92236 \\
BVAR & 0.92528 \\
VECM & 0.92974 \\
VAR-GARCH & 0.95731 \\
VEC-GARCH & 0.96375 \\
\hline
\end{tabular}

Table 10: Optimal Hedge Ratios from different Models

\begin{tabular}{ccccccc}
\hline Method & OHR & One-Day & Five-Day & Ten-Day & Fifteen-Day & Twenty-Day \\
\hline OLS & 0.92236 & $0.00005 \%$ & $0.00020 \%$ & $0.00053 \%$ & $0.00054 \%$ & $0.00062 \%$ \\
VAR & 0.92528 & $0.00003 \%$ & $0.00019 \%$ & $0.00050 \%$ & $0.00052 \%$ & $0.00060 \%$ \\
VECM & 0.92974 & $0.00001 \%$ & $0.00017 \%$ & $0.00047 \%$ & $0.00049 \%$ & $0.00057 \%$ \\
VAR-GARCH & 0.95731 & $-0.00011 \%$ & $0.00005 \%$ & $0.00024 \%$ & $0.00028 \%$ & $0.00034 \%$ \\
VEC-GARCH & 0.96375 & $-0.00014 \%$ & $0.00003 \%$ & $0.00018 \%$ & $0.00024 \%$ & $0.00029 \%$ \\
\hline
\end{tabular}

Table 11: Mean Return for within sample

\begin{tabular}{ccccccc}
\hline Method & OHR & One-Day & Five-Day & Ten-Day & Fifteen-Day & Twenty-Day \\
\hline OLS & 0.92236 & $0.000185 \%$ & $0.000047 \%$ & $0.000034 \%$ & $0.000029 \%$ & $0.000028 \%$ \\
VAR & 0.92528 & $0.000184 \%$ & $0.000047 \%$ & $0.000032 \%$ & $0.000028 \%$ & $0.000026 \%$ \\
VECM & 0.92974 & $0.000184 \%$ & $0.000046 \%$ & $0.000029 \%$ & $0.000025 \%$ & $0.000021 \%$ \\
VAR-GARCH & 0.95731 & $0.00019 \%$ & $0.000034 \%$ & $0.000016 \%$ & $0.000011 \%$ & $0.000009 \%$ \\
VEC-GARCH & 0.96375 & $0.000189 \%$ & $0.000032 \%$ & $0.000014 \%$ & $0.000009 \%$ & $0.000007 \%$ \\
\hline
\end{tabular}

Table 12: Variance Return for within sample 


\begin{tabular}{ccccccc}
\hline Method & OHR & One-Day & Five-Day & Ten-Day & Fifteen-Day & Twenty-Day \\
\hline OLS & 0.92236 & $95.30 \%$ & $98.91 \%$ & $99.24 \%$ & $99.33 \%$ & $99.37 \%$ \\
VAR & 0.92528 & $95.31 \%$ & $98.94 \%$ & $99.28 \%$ & $99.38 \%$ & $99.41 \%$ \\
VECM & 0.92974 & $95.31 \%$ & $98.99 \%$ & $99.34 \%$ & $99.44 \%$ & $99.48 \%$ \\
VAR-GARCH & 0.95731 & $95.23 \%$ & $99.24 \%$ & $99.63 \%$ & $99.75 \%$ & $99.79 \%$ \\
VEC-GARCH & 0.96375 & $95.19 \%$ & $99.27 \%$ & $99.68 \%$ & $99.80 \%$ & $99.85 \%$ \\
\hline
\end{tabular}

Table 13: Percentage in Variance Reduction for within sample

\begin{tabular}{ccccccc}
\hline Method & OHR & One-Day & Five-Day & Ten-Day & Fifteen-Day & Twenty-Day \\
\hline OLS & 0.92236 & $0.00001 \%$ & $-0.00271 \%$ & $-0.00521 \%$ & $-0.00612 \%$ & $-0.00727 \%$ \\
VAR & 0.92528 & $0.00018 \%$ & $-0.00254 \%$ & $-0.00496 \%$ & $-0.00587 \%$ & $-0.00699 \%$ \\
VECM & 0.92974 & $0.00043 \%$ & $-0.00228 \%$ & $-0.00457 \%$ & $-0.00549 \%$ & $-0.00659 \%$ \\
VAR-GARCH & 0.95731 & $0.001988 \%$ & $-0.00068 \%$ & $-0.00219 \%$ & $-0.00314 \%$ & $-0.00404 \%$ \\
VEC-GARCH & 0.96375 & $0.00235 \%$ & $-0.00031 \%$ & $-0.00163 \%$ & $-0.00259 \%$ & $-0.00345 \%$ \\
\hline
\end{tabular}

Table 14: Mean Return for out of sample

\begin{tabular}{ccccccc}
\hline Method & OHR & One-Day & Five-Day & Ten-Day & Fifteen-Day & Twenty-Day \\
\hline OLS & 0.92236 & $0.000097 \%$ & $0.000027 \%$ & $0.000022 \%$ & $0.000022 \%$ & $0.000025 \%$ \\
VAR & 0.92528 & $0.000098 \%$ & $0.000026 \%$ & $0.000020 \%$ & $0.000020 \%$ & $0.000023 \%$ \\
VECM & 0.92974 & $0.000099 \%$ & $0.000024 \%$ & $0.000018 \%$ & $0.000018 \%$ & $0.000020 \%$ \\
VAR-GARCH & 0.95731 & $0.000112 \%$ & $0.000017 \%$ & $0.000008 \%$ & $0.000006 \%$ & $0.000007 \%$ \\
VEC-GARCH & 0.96375 & $0.000116 \%$ & $0.000016 \%$ & $0.000007 \%$ & $0.000005 \%$ & $0.000005 \%$ \\
\hline
\end{tabular}

Table 15: Variance Return for out of sample

\begin{tabular}{ccccccc}
\hline Method & OHR & One-Day & Five-Day & Ten-Day & Fifteen-Day & Twenty-Day \\
\hline OLS & 0.92236 & $97.89 \%$ & $99.46 \%$ & $99.52 \%$ & $99.49 \%$ & $99.46 \%$ \\
VAR & 0.92528 & $97.88 \%$ & $99.49 \%$ & $99.56 \%$ & $99.54 \%$ & $99.49 \%$ \\
VECM & 0.92974 & $97.85 \%$ & $99.52 \%$ & $99.61 \%$ & $99.59 \%$ & $99.56 \%$ \\
VAR-GARCH & 0.95731 & $97.57 \%$ & $99.66 \%$ & $99.83 \%$ & $99.85 \%$ & $99.85 \%$ \\
VEC-GARCH & 0.96375 & $97.48 \%$ & $99.67 \%$ & $99.86 \%$ & $99.89 \%$ & $99.89 \%$ \\
\hline
\end{tabular}

Table 16: Percentage in Variance Reduction for out of sample 

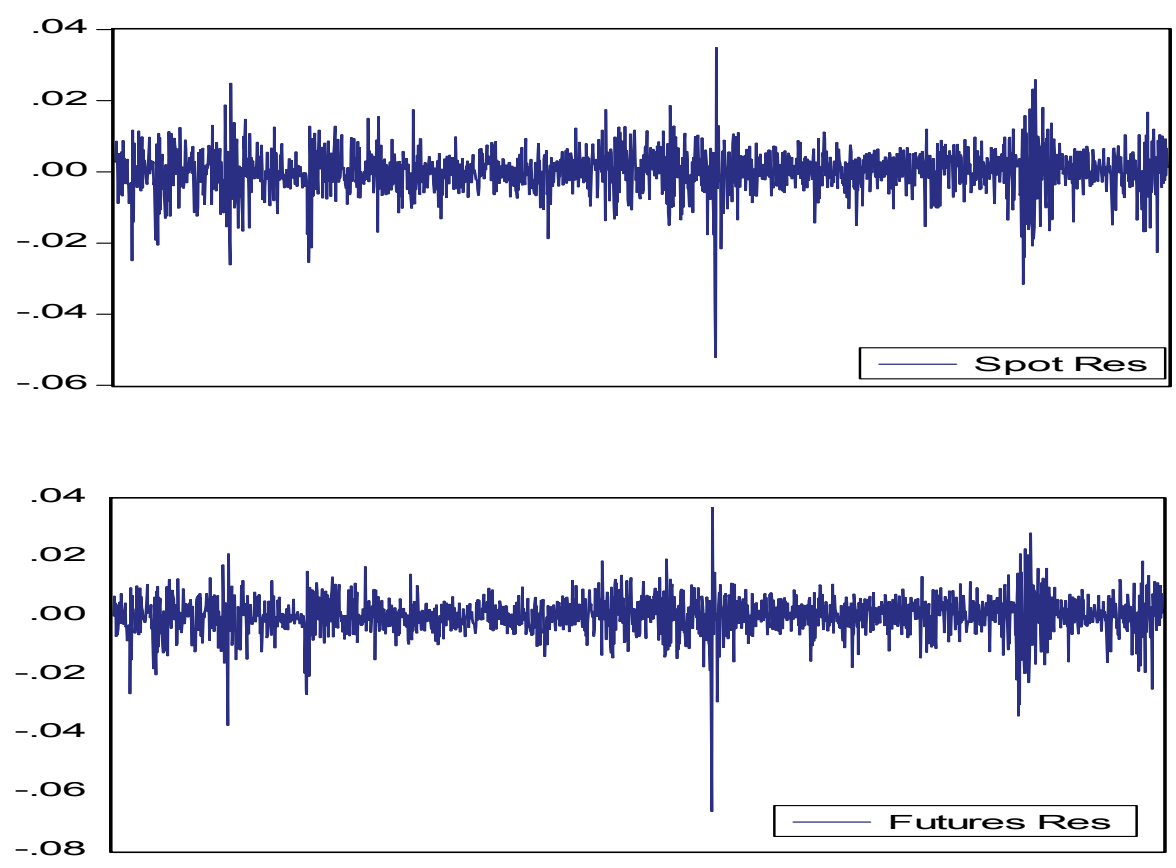

Figure 1: Residual series from Spot and Future equation in Bivariate VAR model
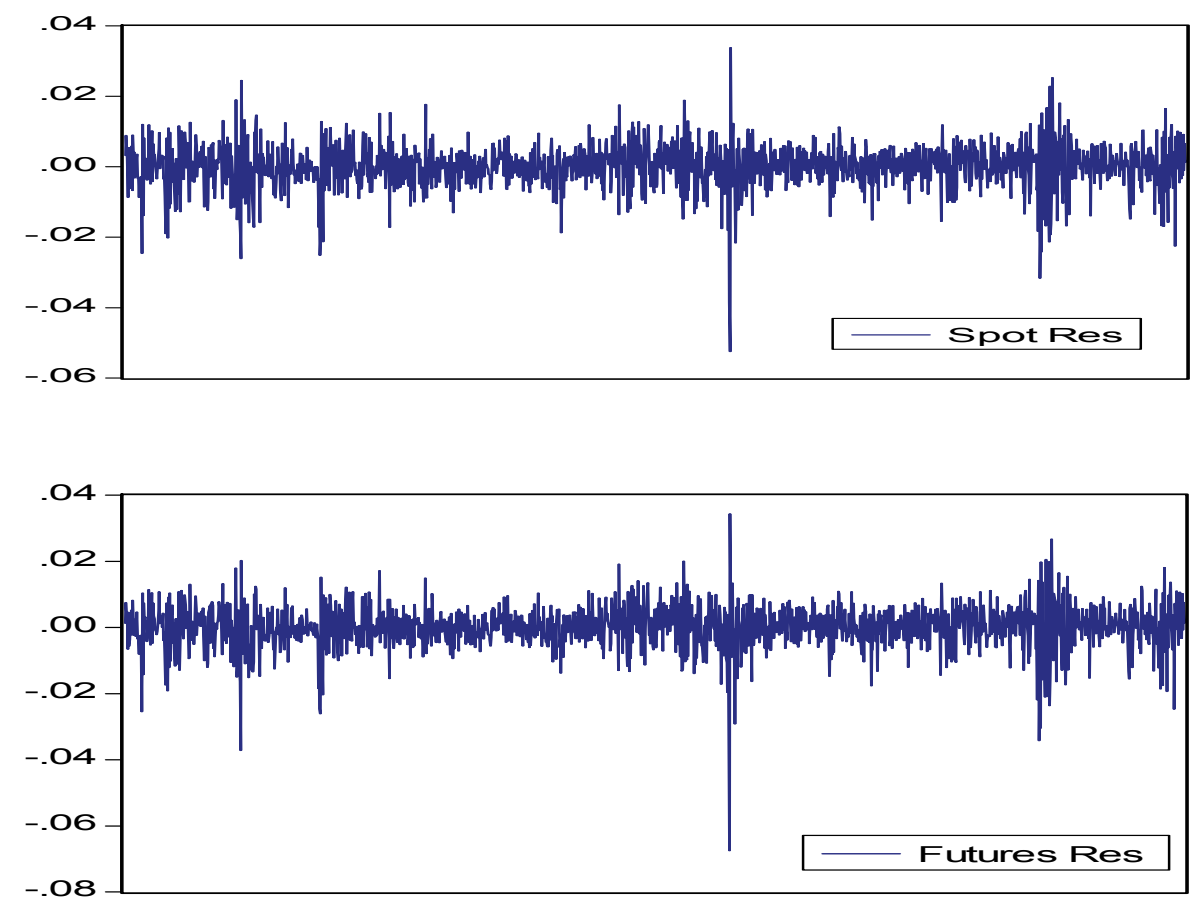

Figure 2: Residual series from Spot and Future equation in VECM model 